\title{
Corrigendum: Provocation to Dialog in a Third Space: Helping Teachers Walk Toward Equity Pedagogy
}

\author{
Tara Ratnam* \\ Independent Researcher, Mysuru, India
}

Keywords: teacher learning, equity pedagogy, dialog, third space, hybridization, lev vygotsky, Mikhail Bakhtin

\section{A corrigendum on}

Provocation to Dialog in a Third Space: Helping Teachers Walk Toward Equity Pedagogy by Ratnam T. (2020). Front. Educ. 5:569018. doi:10.3389/feduc.2020.569018

In the original article, at Paragraph two under the Section Methodology, Sub Section Analysis, there was an error in page number of an in-text reference, "(ibid., p. 141)" needs to be changed to "(ibid., p. 341)", the correct passage appears below.

The conceptions of teaching that participants had imbibed as students (Lortie, 1975) and in the workplace made them see teaching as delivery of ready-made knowledge. In the view that I brought to the group, knowledge was not something out there but co-constructed in inquiry activities undertaken jointly by students and teacher. These two contrasting views presupposed two constellations of voices from the larger social world (Ratnam, 2016c). These can be captured by what Bakhtin (1981) calls, "authoritative discourse" and "heteroglossia," respectively. They are grounded in different epistemological systems, responsive to different relationships and practices. The authoritative discourse "demands that we acknowledge it, that we make it our own... We encounter it with its authority already fused to it." (Bakhtin, 1981, p. 342). Pedagogically, the practice of "reciting by heart" (ibid., p. 341) corresponds to authoritarian discourse within a structure of hierarchical relationship. Heteroglossia, as pointed out earlier, is dialogic, open to connect with other voices in a dialog horizontally and thus open to growth and change. The pedagogical goal associated with heteroglossia is "retelling in one's own words" (ibid.), where the words of others, playing a role in one's inner speech, gets reaccentuated based on one's own intent (authorship). This is "innerly persuasive discourse" (Bakhtin, 1981, p. 346) as opposed to "authoritative discourse." In the analysis below, notions of "authoritative" and "internally persuasive" discourses provide a heuristic in both the critique of the dominant cultural practice in teacher education, where singular "universal" knowledge is privileged, and its reconstruction in the third space created in OG that acknowledges a pluralistic approach to knowledge.

The authors apologize for this error and state that this does not change the scientific conclusions

Received: 13 November 2021 Accepted: 19 November 2021 Published: 10 December 2021

Citation: Ratnam T (2021) Corrigendum: Provocation to Dialog in a Third Space: Helping Teachers Walk Toward Equity Pedagogy.

Front. Educ. 6:814567. doi: 10.3389/feduc.2021.814567

Publisher's Note: All claims expressed in this article are solely those of the authors and do not necessarily represent those of
their affiliated organizations, or those of the publisher, the editors and the reviewers. Any product that may be evaluated in this
article, or claim that may be made by its manufacturer, is not guaranteed or endorsed by the publisher.

Copyright (C) 2021 Ratnam. This is an open-access article distributed under the terms of the Creative Commons Attribution License (CC BY). The use, distribution or reproduction in other forums is permitted, provided the original author(s) and the copyright owner(s) are credited and that the original publication in this journal is cited, in accordance with accepted academic practice. No use, distribution or reproduction is permitted which does not comply with these terms. 